\title{
Evaluation of Quality Assurance of Activity against Accreditation Norms of the Imaging Services in a Tertiary Care Teaching Hospital
}

\author{
Padmini Kumari B ${ }^{1}$, G Vijay Kumar ${ }^{2}$, K. Ravi Babu ${ }^{2}$ \\ ${ }^{1}$ Senior Resident, Department of Hospital Administration, Kasturba Medical College, Manipal, Karnataka, India \\ ${ }^{2}$ Department of Hospital Administration, Vydehi Institute of Medical Sciences and Research Centre (VIMS \& \\ $\mathrm{RC})$, Bengaluru, India \\ Corresponding Author: Padmini Kumari B
}

\begin{abstract}
Purpose of Study: To study the radiological and imaging services in terms of Quality Assurance in relation to accreditation norms.

Methods: We performed cross sectional evaluation of the data obtained from the participants in the study Semi structured both open and closed ended questionnaire were administered among the participants who were agreed to participate in the study. The questionnaire was formulated to evaluate different parameters of Quality Assurance Programme (QAP). The parameters were divided into structure, process and outcome measures and were derived from literature [National Accreditation Board for Hospitals and Health care Providers during accreditation of healthcare institutions].

Results: The radiology and imaging services of Vydehi Medical College Hospital was established in the year 2002, and was approved by AERB (Atomic Energy Regulatory Board) in the year 2007. The department was renewed by AERB in the year 2012. Checklist was formulated which includes several parameters in terms of structure, process and outcome measures.

Conclusion: Quality assurance programme is to provide good patient timely care and the policies adopted by the department of radiology and imaging service in terms of quality are on par with standard guidelines in our study. Safe and sustainable quality care is the need of the hour and it can be practically achieved by regular monitoring of the quality assurance programme.
\end{abstract}

Key words: Quality assurance; Imaging services; Utilisation; Guidelines; Healthcare

\section{INTRODUCTION}

At a tertiary care hospital, Imaging services are essential parts of the clinical practice. Physicians consistently utilize them in diagnosing and monitoring many diseases. The day-to- day uninterrupted operation of these essential facilities requires proper allocation and management of resources at the same time maintaining the quality. One out of every 4-5 patients utilize imaging service in one form or other and quality of services provided by Radiology department have a direct impact on the level of treatment provided to the patient by the hospital. This is also the service that takes away a large share of total capital investment and is also perhaps the highest single revenue earner among all the services. Quality of services provided by the department of radio diagnosis, therefore, is of utmost importance for the overall quality of patient care in the hospital [1]. Without doubt, radiological technology has evolutionized the practice of medicine\| [2], and most medical disciplines today would be almost unrecognisable in the absence of modern imaging [3].

Medical imaging and interventional radiology have been undergoing rapid advances in recent years. Patients now enjoy 
the benefits of earlier diagnosis and less invasive treatment alternatives with lower morbidity and mortality. The volume and complexity of work are steadily increasing but the supply of the professional workforce is not growing sufficiently to meet this increasing demand. From this perspective, modern radiologists are the victims of their success. This workload/workforce imbalance is one of the factors, which could potentially threaten the quality of care and patient safety [4].

Rapid advances in medical imaging evince a consequent need for timely and high quality anatomical information of the subject's body. High disease prevalence and the population explosion are additional compounding factors that increase the workload upon an insufficient number of skilled medical personnel, especially in developing countries. The performance and financial circumstances of radiology departments in the health care systems of Level four (HCL IV) countries may be compromising the quality of patient care because of a low appreciation of quality management in operational efficiency, image quality and patient radiation dose. It is very important to assure quality management in radiology and also study to develop effective, efficient and sustainable programmes commensurate with the socioeconomic status of the country.

There are certain organizations which have laid down guidelines for proper installation and for safe usage of imaging services in health institutions. AERB (ATOMIC ENERGY REGULATORY BOARD) provides guidelines for appropriate use of X-rays; NABH (National Accreditation Board for Hospitals and Health care) and MCI (Medical council of India) also have guidelines for good functioning of radiological services in a teaching hospital in India.

In this context, the present work is aimed at studying the radiological and imaging services in terms of Quality Assurance in Vydehi Institute of Medical
Sciences and Research Centre (VIMS and $\mathrm{RC})$, Bangalore.

\section{MATERIAL AND METHODS}

A cross sectional study was conducted at scheduled radio diagnostic examination day. The participants in the study were the patients who were used radiological services, and the doctors who were requesting for radiology investigation from various user departments. The study was conducted from January 2015 to December 2016 to assess the satisfaction among the participants regarding radiology and imaging services at VIMS \& RC and to identify key areas for quality improvement. Before conducting the study, verbal consent was taken. Semi structured both open and closed ended questionnaire were administered among the participants who were agreed to participate in the study. The participants who did not agree to participate were excluded from the study.

The questionnaire was formulated to evaluate different parameters of Quality Assurance Programme (QAP). The parameters were divided into structure, process and outcome measures and were derived from literature [National Accreditation Board for Hospitals and Health care Providers during accreditation of healthcare institutions]. The questionnaire was given to experts for their suggestions and opinions. The questionnaire was distributed to patients who were willing to participate in the survey at the time of collection of their report. The purpose of the study was explained to the participants before distributing the questionnaire to get their full co-operation and prompt answers. The participants were assured of the confidentiality of their identity and responses.

\section{Limitations of the Study}

As it is an exhaustive study following are the limitation for the study.

- Only four investigation modalities were included in the study (X-RAY, USG, $\mathrm{CT}$, and MRI). 
Padmini Kumari B et.al. Evaluation of quality assurance of activity against accreditation norms of the imaging services in a tertiary care teaching hospital.

- The survey method/questionnaire is subjective and prone to definitive bias from individual perception towards patient care and issues related to services provided. The survey is carried out at the time of collection of report only to identify the key areas for quality improvement, the survey data is not put to any statistical test.

\section{RESULTS AND OBSERVATIONS}

Vydehi Institute of Medical Sciences and Research Centre (VIMS \& RC) Hospital is a 1200 bedded multispecialty tertiary care center. The radiology and imaging services of Vydehi Medical College Hospital was established in the year 2002, and was approved by AERB (Atomic Energy Regulatory Board) in the year 2007.
The department was renewed by AERB in the year 2012 .

\section{QUALITY ASSURANCE PROGRAMME}

The department of radiology follows some policies in providing imaging services. We have assessed the QAP of the present setting considering these policies. Checklist was formulated which includes several parameters in terms of structure, process and outcome measures. [5] The parameters were subdivided wherever necessary and adherence to these checked to identify the gaps and possible avenues of improvement in the department of radiology and imaging services of Vydehi medical college hospital.

\section{CHECK LIST TO ASSESS QAP}

\begin{tabular}{|c|c|c|c|c|}
\hline Sl.no & Parameter & $\begin{array}{l}\text { No compliance } \\
{[0]}\end{array}$ & $\begin{array}{l}\text { Partial compliance } \\
{[5]}\end{array}$ & $\begin{array}{ll}\text { Full compliance } \\
{[10]}\end{array}$ \\
\hline 1 & Physical structure[conformance to AERB guidelines] & & & $\square$ \\
\hline 2 & $\begin{array}{l}\text { Signages [radiation hazard, PCPNDT act, procedure is on, } \\
\text { metallic prosthesis, etc] }\end{array}$ & & & $\square$ \\
\hline 3 & Waiting area [adequacy, disabled friendly] & & $\square$ & \\
\hline 4 & Privacy[changing room, authorized entry] & & & $\square$ \\
\hline 5 & Equipment [acceptance tests, QC tests] & & & $\square$ \\
\hline 6 & $\begin{array}{l}\text { PPE [lead aprons, gonadal \& thyroid shields, glasses to } \\
\text { workers \& patients] }\end{array}$ & & & $\square$ \\
\hline 7 & $\begin{array}{l}\text { Resuscitation equipment, especially in areas of interventional } \\
\text { radiology }\end{array}$ & & & $\square$ \\
\hline
\end{tabular}

Table 2: Compliance to process parameters

\begin{tabular}{|c|c|c|c|c|}
\hline Sl.no & Parameter & $\begin{array}{l}\text { No compliance } \\
{[0]}\end{array}$ & $\begin{array}{l}\text { Partial compliance } \\
\text { [5] }\end{array}$ & $\begin{array}{ll}\text { Full } & \text { compliance } \\
{[10]} & \\
\end{array}$ \\
\hline \multirow[t]{5}{*}{1} & Patient safety: & & & \\
\hline & a. Patient identification & & & $\square$ \\
\hline & b. Informed consent & & & $\square$ \\
\hline & c. History & & & $\square$ \\
\hline & d. Universal precautions & & $\square$ & \\
\hline \multirow[t]{4}{*}{2} & Radiation exposure: & & & \\
\hline & a. Radiographic positioning manual & & & $\square$ \\
\hline & b. Loading factors manual & & & $\square$ \\
\hline & c. ESE & & & $\square$ \\
\hline \multirow[t]{4}{*}{3} & Health worker safety: & & & \\
\hline & a. Radiation dose monitoring & & & $\square$ \\
\hline & b. Needle stick injury & & & $\square$ \\
\hline & c. Pregnant employee & & & $\square$ \\
\hline 4 & Training & & & $\square$ \\
\hline 5 & $\begin{array}{l}\text { Reporting including. Urgent reporting, clinical correlation, } \\
\text { reduction in reporting time. }\end{array}$ & & $\square$ & \\
\hline \multirow[t]{3}{*}{6} & Miscellaneous: & & & \\
\hline & a. Biomedical waste disposal & & $\square$ & \\
\hline & b. Safe storage of narcotic drugs & & & $\square$ \\
\hline
\end{tabular}

Table 3: Compliance to outcome parameters

\begin{tabular}{|l|l|l|l|l|}
\hline Sl.no & Parameter & No compliance [0] & Partial compliance [5] & Full compliance [10] \\
\hline 1 & RRAP[reject repeat analysis program] & & $\square$ & \\
\hline 2 & Duplicate reports & & $\square$ & \\
\hline
\end{tabular}




\section{DISCUSSION}

Radiology and imaging services is part of the service industry and as a service provider one needs to understand quality and delivery of service. This includes knowledge of customer service, customer satisfaction and all its related issues as well as quality assurance and improvement issues [6].

Hoe in his study in 2007 concluded that it is necessary for the radiologist to understand the difference between service quality and service delivery in radiology. Quality in service is only one component of service delivery in radiology. Knowledge of quality assurance in radiology and knowing how to implement and maintain a quality level based on standards set by an external body e.g., JCI (Joint Commission International), as well as knowing how to implement continuous quality improvement programs in the department are also important. All these processes and programs need to be implemented to ensure high quality in service and good service delivery to customers besides improving financial performance of the department. The increased costs of implementing a quality program in a department may be offset by increased patient revenues or cost efficiencies elsewhere [7]. The practice of diagnostic imaging is undergoing rapid change in recent years due to technological advances, workload escalation, workforce shortage, globalization, corporatization, commercialization and commoditization of healthcare [4].

In 2005 N Pongnapang concluded in his study that practical guidelines for better image quality in computed radiography is mainly concerned with the professional skills of the users and the establishment of an efficient quality control program specifically designed to produce the best quality of clinical images. Another important factor he stressed is the level of teamwork among the users. Radiologists should support and encourage staff in the radiology department to appreciate the importance of an effective quality control program. In addition, radiographers who utilise the technology should also receive proper training on developing professional skills concerning CR technology and must also play an important role in the quality control program. A successful digital radiology enterprise will undoubtedly earn immeasurable benefits from an effective quality control program and skilful radiographers who correctly utilise the technology [7].

In commentary by Govindji R. Jankharia [8] in 2008 he concluded that in the next decade, conventional radiology will have a very limited role to play, being mainly restricted to chest $\mathrm{x}$-rays and bedside radiography. He also stressed the need and utilization of radiological services in an Indian perspective.

According to Daniel L. Rubi (2011), Quality in radiology encompasses many dimensions, including appropriateness of the procedure, the protocol used to perform it, accuracy of the interpretation, communication of the results, and measuring and monitoring performance improvement in quality, safety, and efficiency. Computer applications to measure and improve quality can be successfully deployed. Informatics methods should not be regarded as futuristic developments on the horizon; such applications are already in routine use at many institutions and will likely become more prevalent in the future. Ultimately, as radiologists, quality is not just our goal, it is our responsibility, and deploying informatics methods will help us achieve our objectives [9].

With implementation of radiology workflow management system, Halsted et al [10] has shown significant improvement in radiology workflow with operational benefits, such as reduced reading times, improvements in the timeliness of care (both actual and as perceived by patients), and reduced interruptions to radiologists. Secondary benefits, such as documenting communication about a case and facilitating 
review of results, can also promote more timely and effective care.

To manage the limited resources successfully, radiologists and hospital administrator has to work in collaboration to achieve desired outcome in quality care and patient safety. The volume and complexity of work are steadily increasing but the supply of the professional workforce is not growing sufficiently to meet this increasing demand. This workload/workforce imbalance is one of the factors, which could potentially threaten the quality of care and patient safety [4]. From this perspective, modern radiology department are suffering without proper administrative support.

Horea Craciun et al in 2015 [11] in their study concluded that the field of radiology is rapidly evolving due to technological advances and the globalisation of healthcare. This ongoing development greatly affects the quality of care and service delivery. Doctors and professional organisations should display initiative and oversee and tackle challenging conditions in an effective manner to safeguard patient safety and standards of care. The quality of a radiological report relies on the various important steps outlined above. The essence of risk management is to survey all potential reasons for an inaccurate report in advance so that procedures can be put in place to prevent them. More importantly, the medical organisation offering radiology services needs to allow innovation and responsive measures that can improve radiology.

Jonathan B et al concluded in his study that the goal of quality improvement is to do the right thing in a timely fashion for every patient every time. The basic framework and tools described in this article can empower the radiologist to continuously improve his or her practice environment. Quality improvement is not a passive process; rather, it requires a careful, dedicated, and continuously planned effort by a number of skilled and committed team members. This process can be sustained by offering rewards and celebrating successes, with all lessons learned disseminated throughout the department or organization [12].

In 2013, a study in India on QAP in a tertiary care hospital in radiology department by Pankaj Arora concluded [5] that Quality in medical imaging is aptly defined as a timely access to and delivery of integrated and appropriate radiological studies and interventions in safe and responsive facility and prompt delivery of accurately interpreted reports by capable personnel in an efficient, effective and sustainable manner. The different components of the definition cover the aspects which should be catered for when devising a QAP for Radiology Department. The commitment of the top leadership at the level of the department as well as hospital is essential for survival of such a program. The formation of quality assurance manual is absolutely necessary to operationalize such a program. And such a documented QAP is required to provide effective, efficient, timely and safe services to the patients as well as community.

In our study also we used the check list to assess the QAP in radiology and imaging department at VIMS \& RC hospital choosing the parameters structure, process and outcome as per NABH guidelines. We found that QAP in the department of radiology and imaging was appropriate and compliant to the standard guidelines. It was also found in our study that the staffs in the department of radiology and imaging services were satisfied with the existing Quality Assurance present in the department. There is more scope for improvement in terms of universal precautions, reporting and biomedical waste disposal. Constant deliberations and coordination is needed among the department and hospital administration in this regard.

\section{CONCLUSION}

Quality assurance programme is to provide good patient timely care and also 
policies adopted by the department of radiology and imaging service in terms of quality are on par with standard guidelines. But there are some deficiencies found that the department is lacking proper policy for issuing of reports, the appointment system is not satisfactory and also no proper policy of issuing personnel protective equipments during investigations.

In spite of some limitations in our study the department of radiology and imaging service has got good physical infrastructure facilities, policies and procedure and QAP. Utilization of radiology and imaging services are on par with standard guidelines. Maintaining the quality care according to recommended guidelines and hospital policies in collaboration with hospital administration is essential in giving good patient care. Safe and sustainable quality care is the need of the hour and it can be practically achieved by regular monitoring of the quality assurance programme.

\section{ACKNOWLEDGEMENTS:}

We acknowledge the great help provided by Dr Sreenivas T in writing this manuscript

\section{Conflict of Interest: None}

\section{Source of Funding: None}

\section{REFERENCES}

1. S.K Joshi. Quality management in hospitals. $2^{\text {nd }}$ edition. New Delhi: Jaypee; 2014.

2. Amis ES, Jr., Butler PF, Applegate KE et al. American College of Radiology white paper on radiation dose in medicine. $\mathrm{J}$ Am Coll Radiol 2007; 4: 272-84.

3. Cherryman G: Imaging in primary care. $\mathrm{Br} \mathbf{J}$ Gen Pract 2006; 56: 563-4.
4. Lau LS. Leadership and management in quality radiology. Biomed Imaging Interv. J. 2007; 3(3):e21.

5. Arora P, Quality Assurance Programme in Radiodiagnosis in a Tertiary Care Hospital in India. Int $\mathbf{J}$ Res Foundation Hosp Healthc Adm 2013; 1(1):8-12.

6. Hoe J. Quality service in radiology. Biomed. Imaging Interv. J. 2007; 3(3).

7. N Pongnapang. Practical guidelines for radiographers to improve computed radiography image quality. Biomed. Imaging Interv. J. 2005; 1(2:e12.

8. Govindji R.Jankharia. Commentary Radiology in India: The Next Decade. Indian J Radiol Imaging. 2008 Aug; 18(3):189-191.

9. Daniel L. Rubin. Informatics in Radiology Measuring and Improving Quality in Radiology: Meeting the Challenge with Informatics. Radiographics 2011 Oct; 31(6):1511-27.

10. Mark J. Halsted, Craig M. Froehle. Design, Implementation, and Assessment of a Radiology Workflow Management System. AJR 2008; 191:321-327.

11. Horea Craciun, Kshitij Mankad, Jeremy Lynch. Risk management in radiology departments. World J Radiol 2015 June 28; 7(6): $134-138$.

12. Jonathan B. Kruskal, Ronald Eisenberg et al. Quality Initiatives Quality Improvement in Radiology: Basic Principles and Tools Required to Achieve Success. Radiographics Oct 2011; 31(6):1499-509.

How to cite this article: Padmini Kumari B, G Vijay Kumar, K. Ravi Babu. Evaluation of quality assurance of activity against accreditation norms of the imaging services in a tertiary care teaching hospital. Int J Health Sci Res. 2021; 11(9): 172-177. DOI: https://doi.org /10.52403/ijhsr.20210926 